\title{
Truncus Arteriosus with Partial Anomalous Pulmonary Venous Connection and Patent Ductus Arteriosus
}

\author{
David Angel Ortiz Ruiz ${ }^{1}$, Davide Calvaruso ${ }^{2}$, Caruso Elio ${ }^{2}$, and Salvatore Agati ${ }^{2}$ \\ ${ }^{1}$ Mediterranean Pediatric Heart Center - Bambino Gesù \\ ${ }^{2}$ Mediterranean Pediatric Heart Center - Bambino Gesù
}

January 5, 2021

\begin{abstract}
The association of anomalous pulmonary venous connections and truncus arteriosus is extremely rare and can complicate the surgical management of these patients. We report clinical findings and surgical approach in a female newborn with truncus arteriosus, patent ductus arteriosus with normal aortic arch, and partial anomalous pulmonary venous connection.
\end{abstract}

\section{Introduction:}

Truncus arteriosus is a rare congenital heart disease, associated cardiac anomalies enhance diagnosis and management a real challenge. Few cases reports have been described in literature of truncus arteriosus associated with anomalous pulmonary venous connection. We describe a particular case of truncus arteriosus type I plus partial anomalous venous connection and patent ductus arteriosus, reinforcing the importance of an adequate pre surgical study.

\section{Introduction:}

Truncus Arteriosus (TA) is a rare congenital heart disease, representing less than $3 \%$ of all congenital cardiac malformations, ${ }^{1,2}$ very rarely associated with anomalous pulmonary venous connections (APVC). This association can complicate the surgical management of these patients. Indeed, associated cardiac anomalies, as APVC, represents a risk factors for death at surgical repair. In the absence of these associated lesions, TA can be repaired with an excellent surgical outcome in the neonatal and early infancy period. ${ }^{2}$

We present a case of a neonate with TA, patent ductus arteriosus (PDA), and normal aortic arch and partial anomalous pulmonary venous connection (PAPVC).

In their 1965 report, the Van Praagh observed an inverse development of the fourth and sixth pharyngeal arches in hearts with a common arterial trunk. In specimens with a well-developed aortic arch (fourth arch derivative), the ductus arteriosus (sixth arch derivative) was nearly always absent, whereas when a large patent ductus was present, the aortic arch was interrupted. This inverse relationship has been explained on the basis of blood flow patterns in the developing heart and truncus. In clinical series of truncus repair, there has been little mention of this finding, and it is generally known to be the case that truncus with a normal aortic arch and a patent ductus is a rare echocardiographic and surgical finding. ${ }^{3}$

To our knowledge, few cases of TA in association with APVC has been reported. One of the first pathologic data series was presented by Bharati et al. ${ }^{4}$ followed by the documents presented by Berdjis et al. ${ }^{5}$ and Conte et al. ${ }^{6}$ with a single case report each, presented in 1996 and 1997 respectively. In 1999 Litovsky et al. ${ }^{1}$ presented the largest cases series of patients with this rare cardiac association, making a detail description of the clinical approach and evolution. Recent studies demonstrate that an accurate diagnosis, initially 
delineated on echocardiography and implemented by computed tomography or cardiac magnetic resonance, if necessary, are essential to optimize an early repair improving surgical outcome. ${ }^{7,8}$

\section{Case Report:}

A newborn female with antenatal diagnosis of TA was delivered at full term weighting $3.3 \mathrm{Kg}$. After birth a transthoracic echocardiography reported TA type I Collet Edwards ${ }^{4}$ (defined as having a confluent pulmonary segment arising from the common arterial trunk), bicuspid semilunar valve with mild truncal valve insufficiency, patent ductus arteriosus ${ }^{3}$ with a normal aortic arch and a moderate dilatation of a patent cardinal vein (Figure 1 - 2), no hemodynamic repercussion was seen.

On day 8 of life, baby underwent surgery for TA repair. Ventricular septal defect was closed through right ventriculotomy and RV-PA reconstruction was established with a valved conduit (Contegra? \#12). Inotropic support and delayed sternal closure were necessary for a transient right ventricle disfunction. On the $6^{\text {th }}$ postoperative surgery, due to inability for ventilatory and inotropic support weaning and sternal closure, echocardiography control showed an image suggestive of stenosis at level of the distal anastomosis of the Contegra conduit plus the presence of abnormal blood flow at retrocardiac level; therefore, it was decided to perform another surgery

During this new procedure, a left upper pulmonary vein draining into the patent cardinal vein was discovered. After resection, this pulmonary vein was anastomosed directly to the left auricular appendage. Vertical vein was left open. Besides an ampliation patch in the pulmonary arteries confluence was performed without complications. Patient returned to ICU and sternal closure was developed 3 days after; complete ventilatory assistance weaning was successful 14 days later. Before hospital discharge a CT scan was made (Figure 3). Patient was discharged after complete recovery and no abnormalities are reported at the moment.

\section{Comments:}

The surgical management of truncus arteriosus has progressed with the past of years, allowing successful surgeries during the first stage of life. However, presence of additional risk factors, such as coronary abnormalities, hypoplasia, or stenosis of the individual pulmonary veins, mixed-type APVC, and the presence of extracardiac malformations must be assessed thoroughly and considered when discussing prognosis because of survival implications. ${ }^{1}$

With this case report we want to reinforce the necessity of an adequate and early imaging approach in the management of CAT whenever echocardiography is not exhaustive.

\section{Declaration of patient consent}

The investigators certify that all appropriate patient's consent forms have been obtained. Patient's legal representative has given their consent for her images and other clinical information to be reported in the journal. It has been explained that their name and initials will not be published and due efforts will be made to conceal their identity.

\section{Financial support and sponsorship}

None.

\section{Conflicts of interest}

The authors have no conflicts of interest to declare.

\section{References:}

1. Litovsky SH, Ostfeld I, Bjornstad G, Van Praagh R, Geva T. Truncus Arteriosus With Anomalous Pulmonary. Am. J. Cardiol. 1999 March; 83(801-4).

2. Brown JW, Ruzmetov M, Okada Y, Vijay P, Turrentine MW. Truncus arteriosus repair: outcomes, risk factors, reoperation and management. Eur J Cardiothorac Surg. 2001; 20(2)(221-7). 
3. Mello D, McElhinney DB, Parry AJ, Silverman NH, Hanley FL. Truncus Arteriosus With Patent Ductus Arteriosus and Normal Aortic Arch. Ann Thorac Surg. 1997; 64(1808-10).

4. Bharati S, McAllister HAJ, Rosenquist G, Miller RA, Tatooles J, Lev M. The surgical anatomy of truncus. J. Thorac. Cardiovasc. Surg. 1974; 67(501-10).

5. Berdjis F, Wells WJ, Starnes VA. Truncus Arteriosus With Total Anomalous Pulmonary Venous Return and Interrupted Arch. Ann Thorac Surg. 1996; 61(222-2).

6. Conte S, Jensen T, Jacobsen JR, Joyce FS, Lauridsen P, Pettersson, G. One-Stage Repair of Truncus Arteriosus, CAVC, and TAPVC. Ann Thorac Surg. 1997; 63(1781-3).

7. González-López MT, Crucean A, Seale A, McGuirk S. Truncus arteriosus, tricuspid atresia and partial anomalous pulmonary venous drainage: a unique form of univentricular heart. Interact Cardiovasc Thorac Surg. 2015; 21(252-3).

8. Luciani GB, Hoxha S, Lucchese G, Rebonato M, Rossetti L, Faggian G, et al. Neonatal Repair of Truncus Arteriosus With "Scimitar-Like" Mixed Total Pulmonary Venous Return. Ann Thorac Surg. 2014; 97(e167-9).

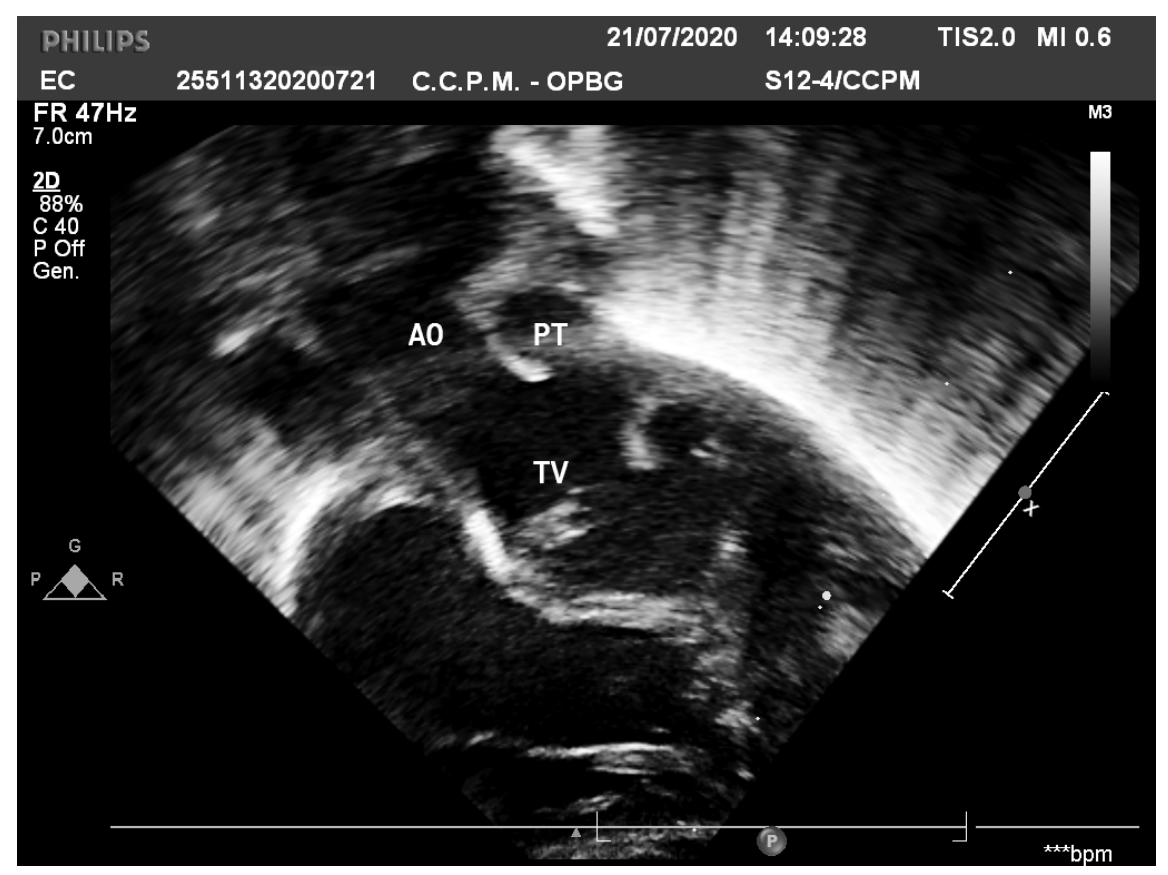



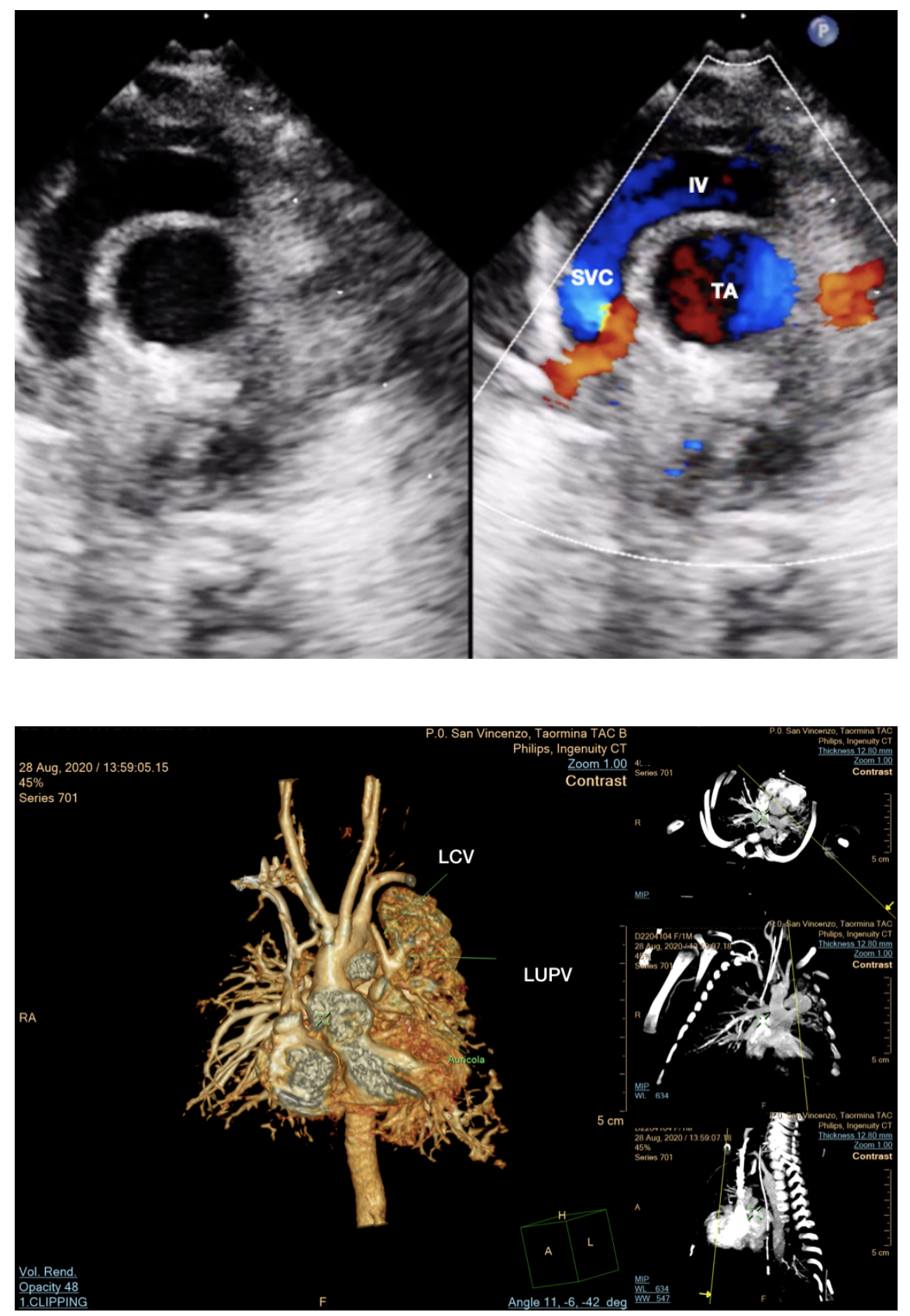